\title{
Glucocorticoid-mediated Repression of Cytokine Gene Transcription in Human Arteritis-SCID Chimeras
}

\author{
Alexander Brack, ${ }^{*}$ Heike L. Rittner, ${ }^{\star}$ Brian R. Younge, ${ }^{\ddagger}$ Christian Kaltschmidt, ${ }^{\S}$ Cornelia M. Weyand, ${ }^{\star}$ and Jörg J. Goronzy \\ $*$ Department of Medicine, Division of Rheumatology, and ${ }^{\ddagger}$ Department of Ophthalmology, Mayo Clinic and Foundation, Rochester, \\ Minnesota 55905; and ${ }^{\S}$ Institute of Biochemistry, University of Freiburg, Freiburg, Germany
}

\begin{abstract}
Giant cell arteritis (GCA) is a vasculitic syndrome that preferentially affects medium and large-sized arteries. Glucocorticoid therapy resolves clinical symptoms within hours to days, but therapy has to be continued over several years to prevent disease relapses. It is not known whether and how glucocorticoids affect the function of the inflammatory infiltrate or why the disease persists subclinically despite chronic treatment. GCA is self-sustained in temporal arteries engrafted into SCID mice, providing a model in which the mechanisms of action and limitations of glucocorticoid therapy can be examined in vivo. Administration of dexamethasone to temporal artery-SCID chimeras for 1 wk induced a partial suppression of $T$ cell and macrophage function as indicated by the reduced tissue concentrations of IL-2, IL-1 $\beta$, and IL-6 mRNA, and by the diminished expression of inducible NO synthase. In contrast, synthesis of IFN- $\gamma$ mRNA was only slightly decreased, and expression of TGF- $\beta 1$ was unaffected. These findings correlated with activation of the $I_{\kappa} B \alpha$ gene and blockade of the nuclear translocation of $\mathrm{NF} K \mathrm{~B}$ in the xenotransplanted tissue. Dose-response experiments suggested that steroid doses currently used in clinical medicine are suboptimal in repressing NFкB-mediated cytokine production in the inflammatory lesions. Chronic steroid therapy was able to deplete the T cell products IL- 2 and IFN- $\gamma$, whereas the activation of tissue-infiltrating macrophages was only partially affected. IL-1 $\beta$ transcription was abrogated; in contrast, TGF- $\beta 1$ mRNA synthesis was steroid resistant. The persistence of TGF- $\beta 1$-transcribing macrophages, despite paralysis of $T$ cell function, may provide an explanation for the chronicity of the disease, and may identify a novel therapeutic target in this inflammatory vasculopathy. (J. Clin. Invest. 1997. 99:2842-2850.) Key words: giant cell arteritis - vasculitis • SCID mouse $\cdot \mathrm{NF} \kappa \mathrm{B} \cdot \mathrm{TGF}-\beta$
\end{abstract}

\section{Introduction}

Giant cell vasculitis (GCA $)^{1}$ is the most frequent inflammatory vasculopathy (1). Inflammatory infiltrates composed of T cells, macrophages, and multinucleated giant cells accumulate in the

Address correspondence to Dr. J.J. Goronzy, Mayo Clinic, 200 First Street, SW, Rochester, MN 55905. Phone: 507-284-1650; FAX: 507284-1086.

Received for publication 3 December 1996 and accepted in revised form 28 March 1997.

The Journal of Clinical Investigation

Volume 99, Number 12, June 1997, 2842-2850 walls of medium-sized and large arteries. The formation of inflammatory infiltrates in the vessel wall leads to destruction of the elastic layers and intimal proliferation, causing vessel occlusion and subsequent infarction. The feared complications of the disease include blindness, stroke, aortic arch syndrome, and rupture of aortic aneurysms. Recent data have indicated that selected CD4+ T cells undergo clonal proliferation in the arterial wall, and secrete IL-2 and IFN- $\gamma(2,3)$. Based upon their functional profile, several populations of CD68+ macrophages have been distinguished in the vascular lesions (4). Macrophages producing IL- $1 \beta$, IL- 6 , and TGF- $\beta 1$ are intermingled with CD4+ IFN- $\gamma+$ T cells, and localize to the adventitial layer of the inflamed artery $(4,5)$. Macrophages accumulating in the tunica media secrete metalloproteinases, and are likely involved in the destruction of elastic membranes and proliferation of smooth muscle cells. Macrophages in the intima of the affected arteries synthesize inducible NO synthase (iNOS). Thus, the emerging disease model suggests that GCA is a $\mathrm{T}$ cell-driven disease in which recognition of an antigen residing in the adventitia leads to macrophage activation and the release of proinflammatory cytokines. These cytokines are assumed to facilitate the acute phase reaction, and to cause the local and systemic symptoms characteristic for this vasculitic syndrome.

A striking feature of GCA is its explicit responsiveness to glucocorticoids. Within hours to days, patients are improved both in terms of the constitutional as well as the ischemic manifestations of the disease. In spite of the prompt therapeutic response, glucocorticoids have to be given to GCA patients over a prolonged period (up to 2-3 yr) before a disease remission can be sustained. Since this vasculitis preferentially affects individuals older than $50 \mathrm{yr}$ of age, side effects of chronic steroid therapy are considerable, and alternative therapeutic approaches are needed.

Understanding the mechanism of action of glucocorticoids in vivo may allow for design of new therapeutic approaches, and could also shed light on pathological events in the chronic inflammatory process. In in vitro studies, the immunosuppressive action of glucocorticoids has been attributed in part to the repression of cytokine gene transcription (6-11). How suppression of cytokine production affects the different cellular components of the inflammatory infiltrate is not understood. In vivo studies in affected tissues are necessary to define the steroid responsiveness of the diverse cells and mediators in an effort to identify those elements that are involved in disease relapses in the first years of the disease. To address these questions, we have established a xenotransplant model of GCA by

1. Abbreviations used in this paper: APDTC, ammonium pyrrolidine dithiocarbamate; GCA, giant cell arteritis; iNOS, inducible nitric oxide synthase; NLS, nuclear localization sequence; TCR, T cell receptor. 
engrafting temporal arteries from GCA patients into SCID mice. In this model, the tissue inflammatory process is maintained, and the mechanisms and limitations of therapeutic interventions can be studied directly.

\section{Methods}

Patients. Temporal artery specimens were obtained from patients undergoing biopsy for diagnostic purposes. The diagnosis of GCA was confirmed by histopathology. Specimens were divided into three to four fragments, and were implanted into NOD-SCID mice.

Mice. NOD-SCID mice were bred in a barrier facility under germ-free conditions. Mice were checked for leakiness by determining serum IgG by ELISA. Mice, ages 5-7 wk, were anesthetized with $3 \mathrm{mg}$ ketamine, and temporal artery specimens were implanted subcutaneously.

Treatment protocols. Control mice and mice assigned to different treatment arms were implanted with specimens from the same patient to control for interindividual variation of the inflammatory response. In the short-term dose-response experiments, treatment was started $3 \mathrm{wk}$ after transplantation. Mice received either $500 \mu \mathrm{l}$ sterile PBS intraperitoneally for seven consecutive days, or dexamethasone at doses of $0.04,0.4$, and $4 \mathrm{mg} / \mathrm{kg}$, respectively. In the long-term treatment protocol, treatment was started on the day of xenotransplantation. Mice were injected with either $500 \mu \mathrm{l}$ sterile PBS intraperitoneally, or with $0.4 \mathrm{mg} / \mathrm{kg}$ dexamethasone for 28 consecutive days. Mice were killed at the completion of the treatment period, and implanted specimens were retrieved and either $(a)$ embedded into OCT compound for histochemical analysis, or $(b)$ RNA-extracted.

In the dithiocarbamate treatment trial, treatment was started $7 \mathrm{~d}$ after transplantation. Mice received an initial dose of $150 \mu \mathrm{M}$ and 1.5 $\mathrm{mM}$, respectively, of ammonium pyrrolidine dithiocarbamate (APDTC) (Sigma Chemical Co., St. Louis, MO) and three maintenance doses of 75 and $750 \mu \mathrm{M}$ APDTC, respectively, at 8, 16, and $24 \mathrm{~h}$. Control mice were sham-treated. Mice were killed after $32 \mathrm{~h}$, and specimens were retrieved.

Antibodies. The following antibodies were used for immunohistochemical staining: polyclonal rabbit anti-human CD3 Ab, 1:100 (DAKO Corp., Carpinteria, CA); monoclonal mouse anti-human CD68 (KP-1) Ab, 1:250 (DAKO); polyclonal rabbit anti-human iNOS $\mathrm{Ab}, 1: 400$ (Affinity Bioreagents, Golden, $\mathrm{CO}$ ); monoclonal mouse anti-human TGF- $\beta 1$ Ab, 1:100 (Antigenix America, Franklin Square, NY); mouse anti-human Rel-A nuclear localization sequence (NLS) $\mathrm{mAb}, 1: 150$; biotinylated rabbit anti-mouse mAb, 1:200; biotinylated swine anti-rabbit mAb, 1:200; and streptavidin peroxidase (all DAKO).

Immunohistochemistry. OCT-embedded temporal artery specimens were cut into $5-\mu \mathrm{m}$ sections, dried in a $37^{\circ} \mathrm{C}$ desiccator, and acetone-fixed for $10 \mathrm{~min}$. Slides were incubated with $1 \%$ paraformaldehyde for $3 \mathrm{~min}$, and endogenous peroxidase was blocked with $0.3 \%$ $\mathrm{H}_{2} \mathrm{O}_{2}$ in sodium azide. Nonspecific binding was reduced by incubation with $5 \%$ normal goat serum for $10 \mathrm{~min}$. Slides were incubated with the primary antibody and with the corresponding secondary antibody for $30 \mathrm{~min}$ each. Anti-CD3 and anti-CD68 stains were developed with streptavidin peroxidase and aminoethylcarbazole and diaminobenzidine, respectively. Anti-Rel-A NLS and anti-TGF-ß1 stains were developed according to the specifications of the manufacturer (Vectastain immunofluorescent red kit; Vector Laboratories Inc., Burlingame, CA). All slides were counterstained with hematoxylin for $1 \mathrm{~min}$, and were mounted with Permount (Baxter Scientific, Deerfield, IL). Negative controls were stained without the primary antibody, and photographs were taken (Axiphot microscope; Zeiss, Oberkochen, Germany). Positive cells were counted, and the tissue area of each counted slide was quantified by algorithms (IBAS image analysis system; Kontron Elektronik, Eching, Germany). Results were expressed as the number of cells per tissue area.

$P C R$ primers and biotinylated probes. Primes and probes were as follows: $\beta$-actin (5': ATG GCC ACG GCT GCT TCC AGC; 3': CAT
GGT GGT GCC GCC AGA CAG; probe: TAC AGG TCT TTG CGG ATG TC), IL-1 $\beta$ (5': GAC ACA TGG GAT AAC GAG GC; 3': GGG ATC TAC ACT CTC CAG CTG; probe: AGC TTT TTT GCT GTG AGT CCC GGA G), IL-2 (5': AAC ACA GCT ACA ACT GGA GC; 3': AGA CTT GTC TAC CTA ATG GA; probe: AGC TAA ATT TAG CAC TTC CTC CAG), IL-6 (5': GAT GTA GCC GCC CCA CAC AGA CAG; 3': CCT CAA ACT CCA AAA GAC GAC CAG TGA TG; probe: GAG AAA GGA GAC ATG TAA CA), TGF- $\beta 1$ (5': AAG TGG ACA TCA ACG GGT TCA CTA; 3': GCT GCA CTT GCA GGA GCG CAC; probe: CAG TAC AGC AAG GTC CTG GCC CTG), IFN- $\gamma$ (5': ACC TTA AGA AAT ATT TTA ATG C; 3': ACC GAA TAA TTA GTC AGC TT; probe: ATT TGG CTC TGC ATT ATT TTT CTG T), T cell receptor (TCR) $\mathrm{C} \alpha$ chain (5': GAA CCC TGA CCC TGC CGT GTA CC; 3': ATC ATA AAT TCG GGT AGG ATC C; probe: AGC AAC AGT GCT GTG GCC TG), IкB $\alpha$ (5': GCT GAA GGA GCG GCT AC; 3': TCC GGC CAT TAC AGG GCT CC; probe: AGG GAG ACC TG G CCT TCC TCA A).

Cytokine semiquantification. RNA was extracted using a commercial kit (Trizol; Life Technologies, Grand Island, NY). cDNA of all samples was diluted to adjust for equal $\beta$-actin copy numbers. Adjusted cDNAs were amplified by PCR using the cytokine-specific primers described above. All primers were human species-specific and did not amplify murine sequences. Samples from treated and untreated mice were always run in parallel. PCR conditions consisted of denaturation at $94^{\circ} \mathrm{C}$ for $1 \mathrm{~min}$, annealing at $55^{\circ} \mathrm{C}$ for $1 \mathrm{~min}$, and extension for $2 \mathrm{~min}$ at $72^{\circ} \mathrm{C}$ for 30 cycles with a final 10 -min extension at $72^{\circ} \mathrm{C}$. In each PCR, serial dilutions of cytokine-specific sequences with known transcript numbers were included. Amplified products were blotted and hybridized with internal probes. PCR products were heat denatured at $94^{\circ} \mathrm{C}$ for $5 \mathrm{~min}$, blotted onto a supported nitrocellulose membrane (Schleicher and Schuell, Keene, NH), and baked at $80^{\circ} \mathrm{C}$ for $1 \mathrm{~h}$ in a vacuum oven. Membranes were transferred into prehybridization solution including denatured salmon sperm DNA for $3 \mathrm{~h}$ ( $55^{\circ} \mathrm{C}$ for $\beta$-actin, IL- $1 \beta$ and $\mathrm{I}_{\kappa} \mathrm{B} \alpha ; 42^{\circ} \mathrm{C}$ for all other cytokines). After prehybridization, cytokine-specific biotinylated probes were added at a concentration of $200 \mathrm{ng} / \mathrm{ml}$. Hybridization was performed overnight at the same temperature as prehybridization. Washing was performed with $2 \times \mathrm{SSC}, 0.1 \times \mathrm{SDS}$ for $10 \mathrm{~min}$ at $42^{\circ} \mathrm{C}$ and for $5 \mathrm{~min}$ at $55^{\circ} \mathrm{C}$. The last wash was omitted for IL-2 and IFN- $\gamma$ blots. Membranes were blocked with a BSA-containing solution, incubated with streptavidinperoxidase, washed twice, developed with nitro blue tetrazolium chloride/bromo-chloro-indolyl-phosphate, and scanned (AMBIS system; Scanalytics, Billerica, MA). The serial dilutions of cytokine sequences with known concentrations were processed in parallel and used as a standard curve to calculate the original transcript number in the specimen.

\section{Results}

Differential sensitivity of $T$ cell and macrophage products to in vivo glucocorticoid treatment. Temporal artery specimens from GCA patients were engrafted in SCID mice to a subcutaneous transplant site. In these xenografts, the disease process continued as demonstrated by the persistence of the typical histomorphology and the ongoing transcription of T cell- and macrophage-derived cytokines (12). T cells in the vascular lesions were of the TH1 subtype, and produced IL-2 and IFN- $\gamma$. IL-4 was rarely detected in the tissue. Macrophage-derived products included IL-1 $\beta$, IL-6, and TGF- $\beta 1$. Persistent transcription for these cytokines was followed for up to 2 mo in the xenografts.

To examine the in vivo effects of glucocorticoids, temporal artery specimens from patients with active GCA were engrafted subcutaneously into four SCID mice, and treatment was initiated $3 \mathrm{wk}$ after the transplantation. The mice were ei- 


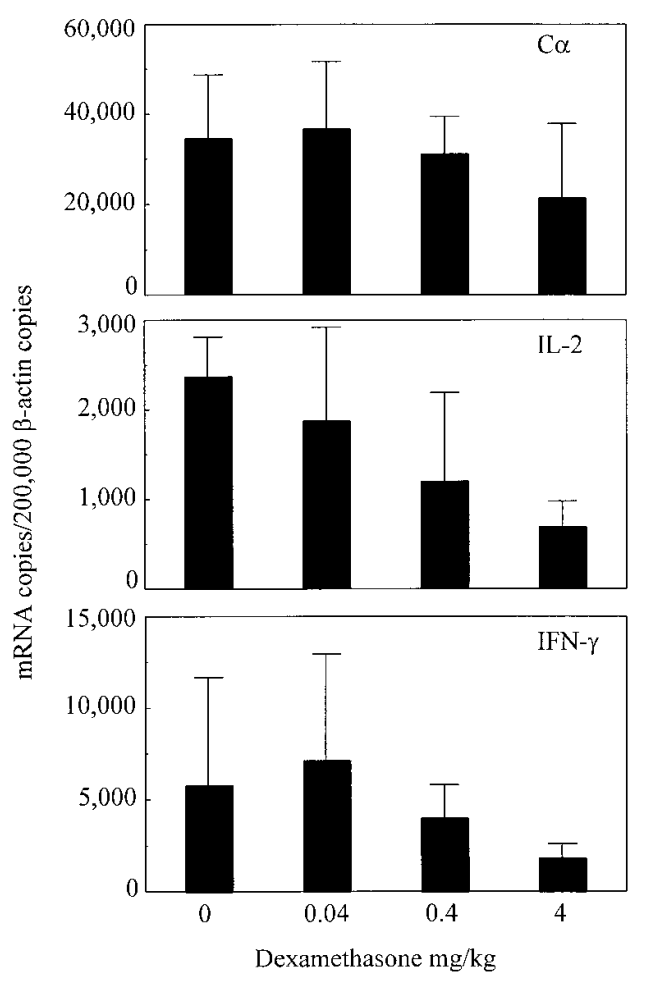

Figure 1. Cytokine transcription in human temporal artery specimens retrieved from glucocorticoidtreated human-mouse chimeras. A temporal artery specimen from a GCA patient was divided into four segments, and each segment was implanted into a NOD-SCID mouse. $3 \mathrm{wk}$ after transplantation, mice were treated with increasing doses of dexamethasone for $1 \mathrm{wk}$. Specimens were retrieved and analyzed for the in situ transcription of lymphokines (left) and monokines (right) by semiquantitative PCR and hybridization. Results are shown as mean of three experiments using temporal artery specimens from three patients. ther sham-injected or received dexamethasone intraperitoneally for $7 \mathrm{~d}$ at doses of $0.04,0.4$, and $4 \mathrm{mg} / \mathrm{kg}$, respectively. Tissue specimens were explanted, analyzed by immunohistochemistry, and mRNA cytokine copy numbers were semiquantified by PCR amplification and dot-blotting. To assure comparability of tissue quantity, $\beta$-actin copy numbers were determined in all retrieved specimens, and cDNA was adjusted to achieve equal $\beta$-actin copy numbers. Results of three independent experiments are summarized in Fig. 1.

As demonstrated by the level of transcription for the TCR $\alpha$ chain, the density of the $T$ cell infiltrate was unaffected by steroid treatment, with the exception of grafts exposed to $4 \mathrm{mg} / \mathrm{kg}$ dexamethasone. With the highest dose of glucocorticoids, $\mathrm{T}$ cell numbers in the inflammatory lesions decreased by 30-35\%. Concentrations of IL-2-specific transcripts decreased in a dose-dependent fashion from a mean of 2,370 copies in untreated animals to a mean of 692 copies in the highest dose group. The suppressive effect of steroids was less pronounced for IFN- $\gamma$-specific sequences. Copy numbers of IFN- $\gamma-$ specific transcripts were unaltered, or only slightly reduced in grafts recovered from mice treated with 0.04 and $0.4 \mathrm{mg} / \mathrm{kg}$ dexamethasone. Only the administration of $4 \mathrm{mg} / \mathrm{kg}$ dexamethasone induced a marked reduction of IFN- $\gamma$ transcription (1,875 copies vs. 5,816 copies in the untreated animal). Thus, administration of steroids resulted in a partial inhibition of T cell-derived cytokines. The inhibition remained incomplete, and even the partial inhibition of the more steroid-sensitive IL-2 with 0.4 $\mathrm{mg} / \mathrm{kg}$ dexamethasone required five times higher doses than those usually used in the treatment of GCA patients.

Tissue-infiltrating macrophages have been found to fall into several categories according to the spectrum of products they synthesize in situ (4). The pattern of mediators produced correlates with a strict topographical arrangement. Macro- phages expressing IL- $1 \beta$, IL- 6 , and TGF- $\beta 1$ mRNA have been mapped to the tunica adventitia. The subset of macrophages accumulating in the intima has been demonstrated to produce iNOS. Macrophage-derived products were sensitive to steroidmediated repression with the exception of TGF- $\beta 1$ mRNA. Treatment with dexamethasone was followed promptly by a reduction in iNOS. Table I summarizes the result of immunohistochemical analysis with iNOS-specific antibodies. The proportion of iNOS + cells declined sharply after steroid therapy. As shown in Fig. 1, the lowest dose of dexamethasone was also sufficient to affect the synthesis of IL-1 $\beta$ mRNA. With 4 $\mathrm{mg} / \mathrm{kg}$ dexamethasone, IL-1 $\beta$ transcription was almost completely inhibited. IL-1 $\beta$ transcripts were downregulated from a mean of 16,839 copies in untreated tissues to a mean of 1,186 transcripts in the highest steroid dosage group. Steroid effects were less apparent for IL-6, which was rather resistant to 0.4

Table I. iNOS Expression in Temporal Artery Tissues Retrieved from Glucocorticoid-treated GCA-SCID Mouse Chimeras

\begin{tabular}{lcc}
\hline Tissue specimen & Dexamethasone & iNOS-expressing cells \\
\hline \multirow{2}{*}{ Patient 1} & 0 & cells $/ \mathrm{mm}^{2}$ \\
& 0.04 & 92 \\
& 0.4 & 11 \\
Patient 2 & 4 & 10 \\
& 0 & 21 \\
& 0.04 & 34 \\
& 0.4 & 25 \\
& 4 & 22 \\
& & 5
\end{tabular}



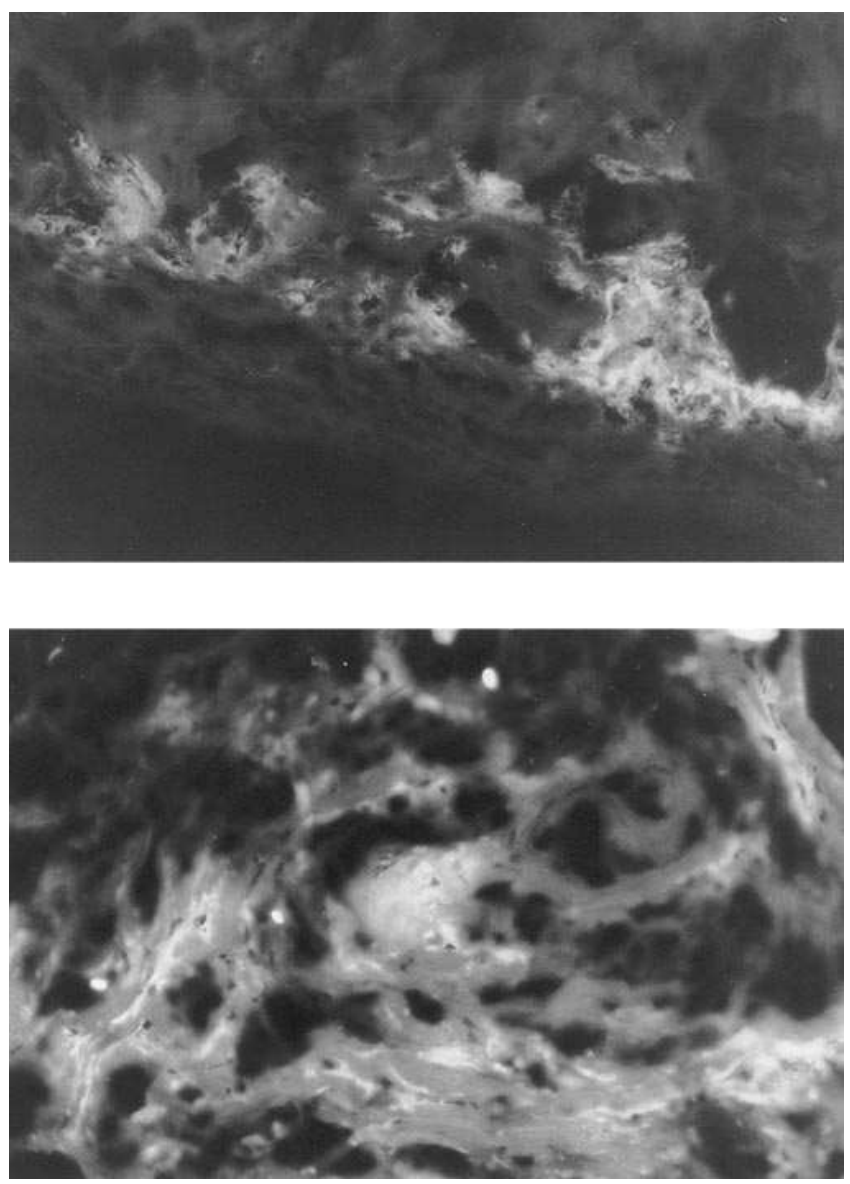

Figure 2. TGF- $\beta 1$ production in temporal artery specimens retrieved from glucocorticoid-treated human tissue-SCID mouse chimera. Temporal artery tissue retrieved from an untreated mouse (top) and a mouse treated with $0.4 \mathrm{mg} / \mathrm{kg}$ dexamethasone for $1 \mathrm{wk}$ (bottom) were stained with anti-TGF- $\beta 1$ antibodies. Production of TGF- $\beta 1$ in the inflammatory infiltrate was not suppressed by glucocorticoids. Immunofluorescence, $\times 400$.

$\mathrm{mg} / \mathrm{kg}$ dexamethasone. With higher doses, IL-6 mRNA copy numbers were reduced from 25,626 to 9,437 . Among all the cytokines analyzed, TGF- $\beta 1$ had a unique position. TGF- $\beta 1$ mRNA production was unaffected by the treatment, suggesting that this cytokine is steroid resistant. Even in the tissues harvested from mice injected with a $7-\mathrm{d}$ course of $4 \mathrm{mg} / \mathrm{kg}$ dexamethasone, TGF- $\beta 1$ transcription persisted with a mean copy number of 7,620 as compared to 9,535 copies in sham-treated animals. The persistence of TGF- $\beta 1$ production in glucocorticoid-treated animals was confirmed at the protein level. Fig. 2 shows temporal artery tissues retrieved from an untreated and a treated mouse stained with an anti-TGF- $\beta 1$ antibody. There was no decline in the number of TGF- $\beta 1$-producing cells after glucocorticoid treatment.

In vivo steroid-mediated regulation of $N F \kappa B$. The antiinflammatory action of steroids has been attributed, at least in part, to the transrepression of cytokine mRNA. Mechanisms underlying the cytokine suppressive effects in vitro are beginning to be understood. Steroids have been shown to induce I $\mathrm{B} \alpha$ transcription, and thereby to reduce the availability of nuclear NFkB leading to a decreased expression of IL-2. To in-

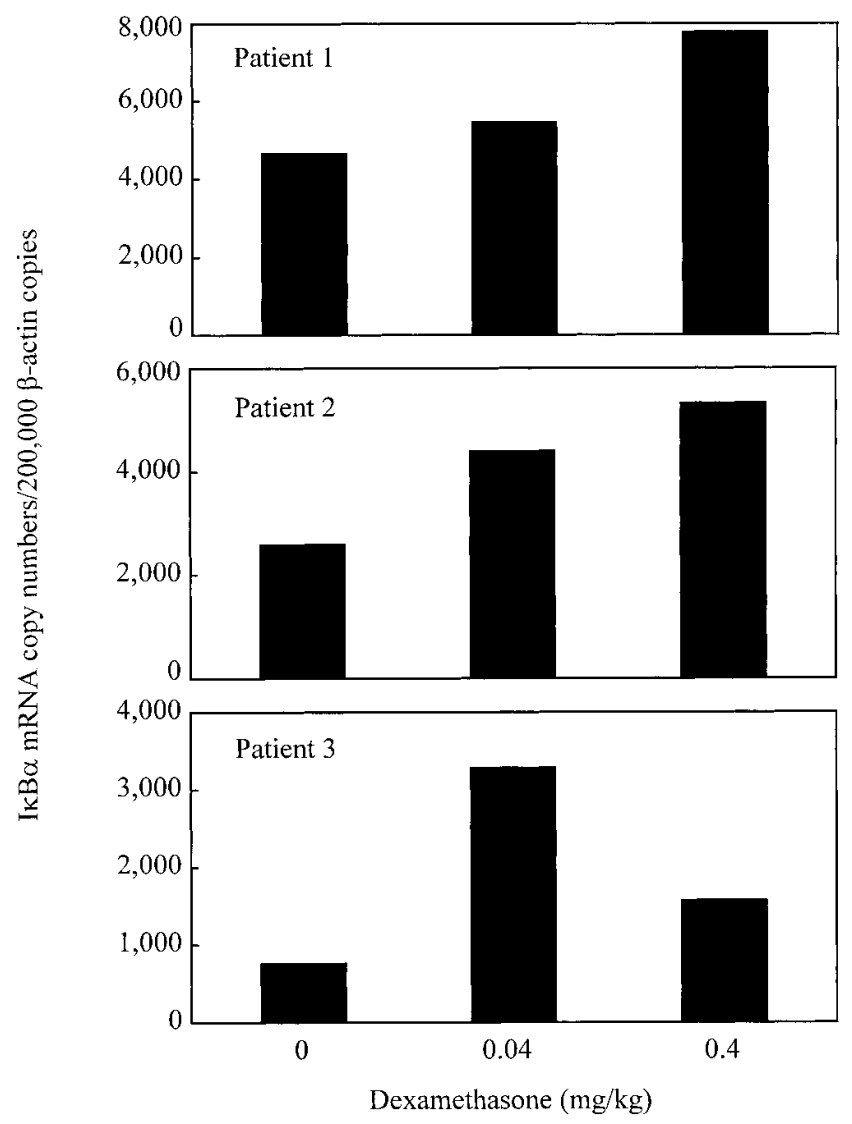

Figure 3. Induction of $\mathrm{I} \kappa \mathrm{B} \alpha$ transcription by dexamethasone in human GCA tissue. Mouse chimeras were generated and treated as described in Fig. 1. Tissue was retrieved and the number of IкB $\alpha$ sequences in the tissue was determined by semiquantitative PCR. Results for three different patients are shown.

vestigate whether this mechanism is functional in vivo, $\mathrm{I}_{\kappa} \mathrm{B} \alpha$ mRNA transcripts were measured in temporal artery grafts from three distinct patients. Mice were either sham-treated or treated with daily injections of 0.04 and $0.4 \mathrm{mg} / \mathrm{kg}$ dexamethasone, respectively, for $1 \mathrm{wk}$. Results from the retrieved tissue specimens are given in Fig. 3. In all three experiments administration of glucocorticoids led to a doubling in the concentration of IкB $\alpha$ mRNA. IкB $\alpha$ induction in the tissue was already achieved with the lower dexamethasone doses. In one patient, $0.04 \mathrm{mg} / \mathrm{kg}$ dexamethasone was sufficient to induce a maximal response.

Steroid-mediated induction of IкB $\alpha$ traps NFкb in the cytoplasm, and thus causes transrepression of steroid-sensitive cytokine genes. Functional NFKB sites in the promoter region have been identified for IL-2, IL-1 $\beta$, IL-6, and iNOS, but are lacking in IFN- $\gamma$ and TGF- $\beta 1$. Interference with the nuclear translocation of $\mathrm{NF \kappa B}$ would thus provide an excellent explanation for the differential modulation of cytokines demonstrated in the GCA tissue.

To further explore whether in vivo glucocorticoid therapy is associated with downregulation of free nuclear NFkb, the nuclear expression of this transcription factor was compared in tissue sections from untreated and treated xenotransplants. Free nuclear $\mathrm{NF \kappa B}$ was immunohistochemically detected through a monoclonal antibody directed against the NLS of 


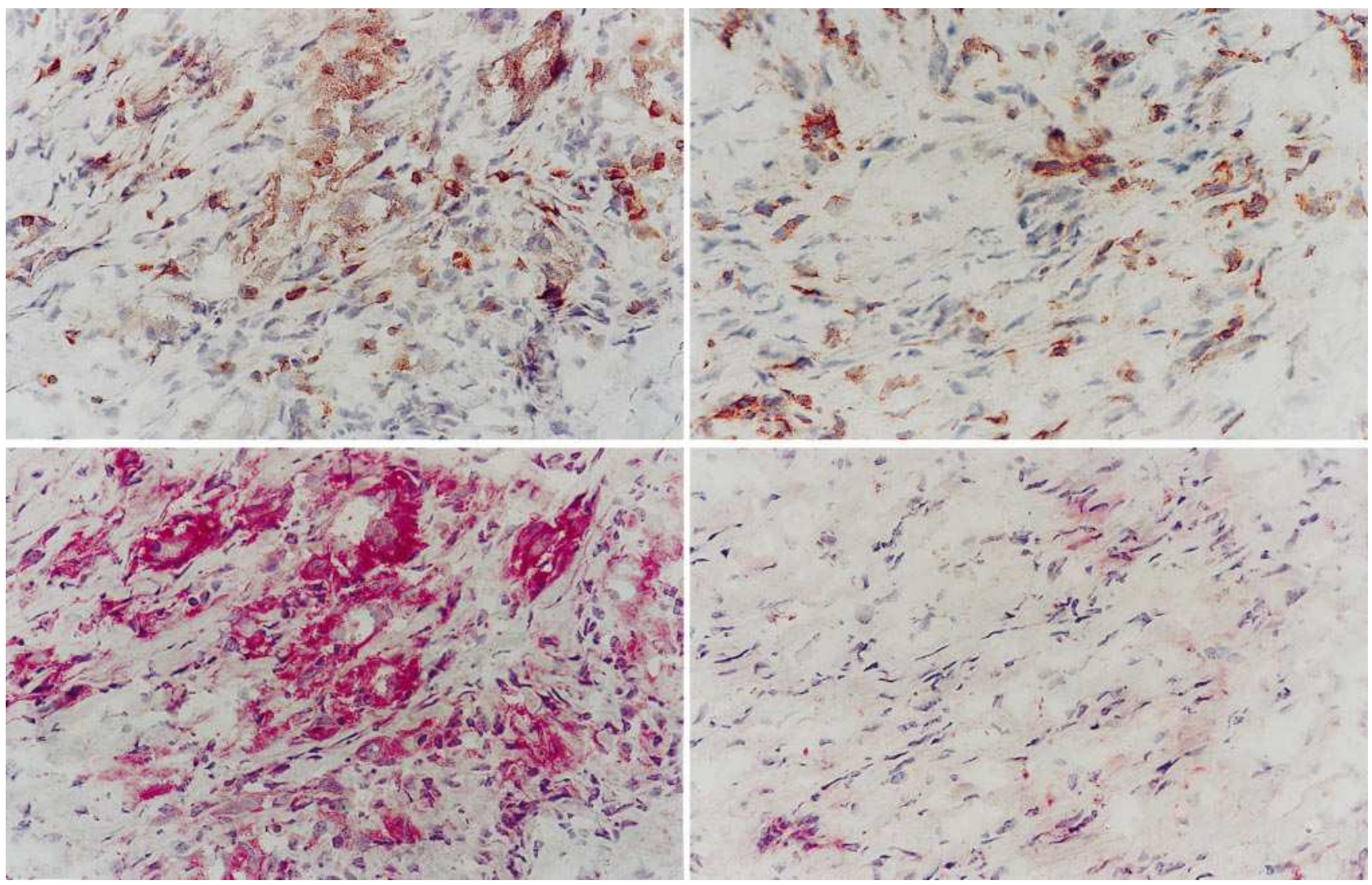

Figure 4. Dexamethasone reduces the availability of free nuclear NFkB in the inflammatory infiltrate of human GCA-mouse chimeras. NODSCID mice were engrafted with temporal artery tissue and treated as described in Fig. 1. Adjacent sections were stained with either anti-CD3 to document the T cell infiltrate (top) or an antibody to the NLS of human ReL-A (bottom) which only recognizes free nuclear NFKB (13). Tissue sections from untreated mice (left) and from mice treated with $0.4 \mathrm{mg} / \mathrm{kg}$ dexamethasone (right) are shown. Nuclear expression of NFkB declined with glucocorticoid treatment. $\times 400$.

the p65 component of NFK (13). The NLS epitope becomes accessible to the antibody when the p50/p65 heterodimer dissociates from IкB $\alpha$. Thus, this immunohistochemical approach specifically stains transcriptionally active NFkB. Temporal artery segments from two different patients were engrafted, and the mice were either sham-injected, or received $0.04,0.4$, and $4 \mathrm{mg} / \mathrm{kg}$ dexamethasone, respectively, for seven consecutive days. Grafts were harvested, sectioned, and stained with rabbit anti-human CD3 to identify tissue-infiltrating T cells (Fig. 4). Adjacent sections were stained with the $\mathrm{mAb}$ specific for free nuclear $\mathrm{NF \kappa B}$. NFкB + cells were markedly reduced, indicating that steroid injections lead to the trapping of $\mathrm{NFKB}$ in the cytoplasm. In tissues retrieved from mice treated with $0.04 \mathrm{mg} /$ $\mathrm{kg}$, free nuclear $\mathrm{NF} \mathrm{B}$ was reduced but still present. High doses of dexamethasone essentially led to the disappearance of nuclear NFkB.

The inhibitory effect of $\mathrm{I}_{\kappa} \mathrm{B} \alpha$ for $\mathrm{NF} \kappa \mathrm{B}$ can be potentiated by APDTC. Dithiocarbamates reversibly suppress the dissociation of IкB $\alpha$ from the latent cytoplasmic form of NFkB (14). To test whether dithiocarbamates induce a similar pattern of cytokine repression as glucocorticoids, SCID mice engrafted with temporal arteries from GCA patients were treated with APDTC for $24 \mathrm{~h}$. IL- 6 and TGF- $\beta 1 \mathrm{mRNA}$ was semiquantified in tissue extracts to examine whether the suppression of IL- 6 and the sparing of TGF- $\beta 1$ transcription can be mimicked by $\mathrm{NF}_{\kappa} \mathrm{B}$ inhibition. Administration of dithiocarbamate to SCID mice carrying xenotransplants resulted in downregulation of IL-6 mRNA synthesis. This effect was already seen with the treatment regimen using a low dose of APDTC (Fig. $5)$. In contrast, TGF- $\beta 1$ was completely unaffected, even with the highest dose in two of three experiments. We have shown recently that IL-6-producing macrophages always cosynthesize TGF- $\beta 1$, excluding a nonspecific toxic effect of APDTC (4). The differential modulation of the two macrophage-derived products lends further support to the model that steroids affect the inflammatory lesions via NFkB specific inhibition.

Persistence of TGF- $\beta 1$-producing macrophages despite successful suppression of $T$ cell function in chronically treated $G C A$. Experiments in the steroid-treated GCA-SCID chimeras are best compatible with transrepression of $\mathrm{NFkB}$-sensitive cytokines, which may be responsible for the prompt improvement of clinical symptoms in steroid-treated patients. Nevertheless, patients need to be maintained on steroids, and they tend to relapse if steroids are discontinued within the first years of treatment. To examine whether the dynamics of the inflammatory infiltrate under steroid treatment allows conclusions on the nature of the chronicity of the disease, we investigated the effects of chronic steroid administration on GCASCID chimeras. Fragments of temporal artery specimens were implanted into SCID mice, and the mice were either treated 


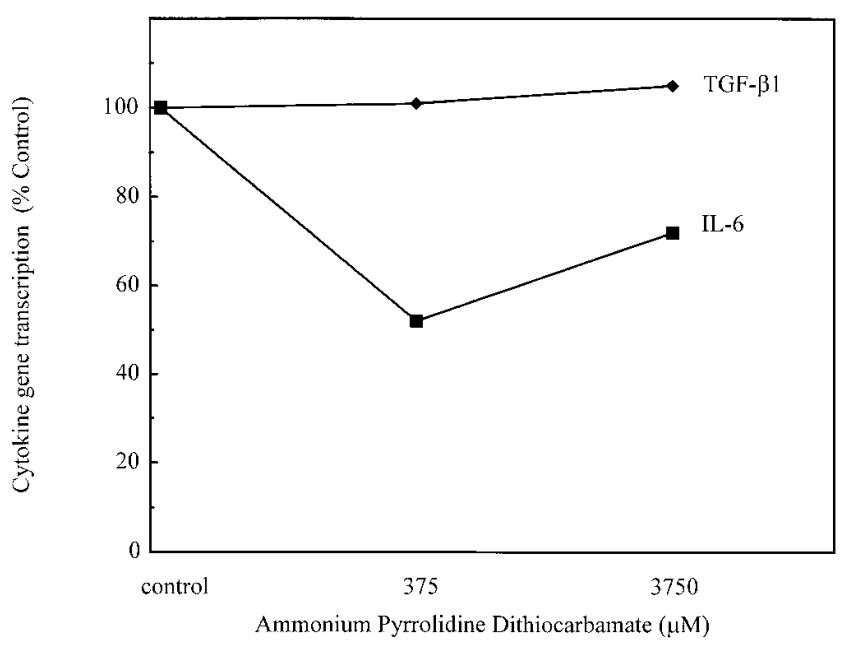

Figure 5. Treatment with dithiocarbamate suppresses in situ production of IL- 6 , but not of TGF- $\beta 1$, in human GCA-mouse chimeras. Human-mouse chimeras were treated for $24 \mathrm{~h}$ with buffer control only or a total dose of 375 and 3,750 $\mu \mathrm{M}$ APDTC, respectively. In situ transcription of IL- 6 and TGF- $\beta 1$ mRNA was semiquantified by PCR and hybridization. Results from one out of three experiments are shown.

with daily injections of sterile PBS, or with $0.4 \mathrm{mg} / \mathrm{kg}$ dexamethasone for $28 \mathrm{~d}$. Prolonged glucocorticoid therapy did not dramatically change the histology of the inflammatory lesion. Fig. 6 demonstrates that an inflammatory infiltrate composed of $\mathrm{T}$ cells and macrophages persists in the treated as well as untreated animals.

Cytokine transcription in the retrieved tissues was semiquantified as described above. A summary of the results from three experiments is shown in Fig. 7. In spite of the persisting $\mathrm{T}$ cell infiltrate, the transcription of TCR $\alpha$ chain sequences in treated mice was minimal with a significant reduction compared to untreated tissue $(P=0.017)$. In parallel, production of IFN- $\gamma$ transcripts essentially ceased $(P=0.047) .4 \mathrm{wk}$ of continuous treatment was thus able to abrogate $\mathrm{T}$ cell function in the vascular lesions, including the NFkB-independent production of IFN- $\gamma$. A different picture emerged for the functional activities of macrophages. The antiinflammatory action of chronic steroid administration was associated with a marked suppression of IL-1 $\beta$ transcription $(P=0.028)$. Synthesis of IL-6 mRNA was significantly reduced $(P=0.028)$ but persisted at low levels. Median copy numbers of IL-6 mRNA were estimated at 10,753 in the untreated tissue samples versus 3,650 in the treated specimens. No therapeutic effect from glucocorticoids was found for TGF- $\beta 1$ mRNA. Even a course of $4 \mathrm{wk}$ of glucocorticoids could not diminish the production of TGF- $\beta 1$ mRNA. There was even a trend for higher concentrations of TGF- $\beta 1$ mRNA in the explants exposed to $4 \mathrm{wk}$ of continuous steroids when compared to untreated temporal artery fragments, however, this trend was not significant. These data demonstrate that macrophages persist in spite of steroid treatment in the arterial tissue, and continue to be activated in the absence of T cell-derived lymphokine production as documented by the in situ synthesis of TGF- $\beta 1$.

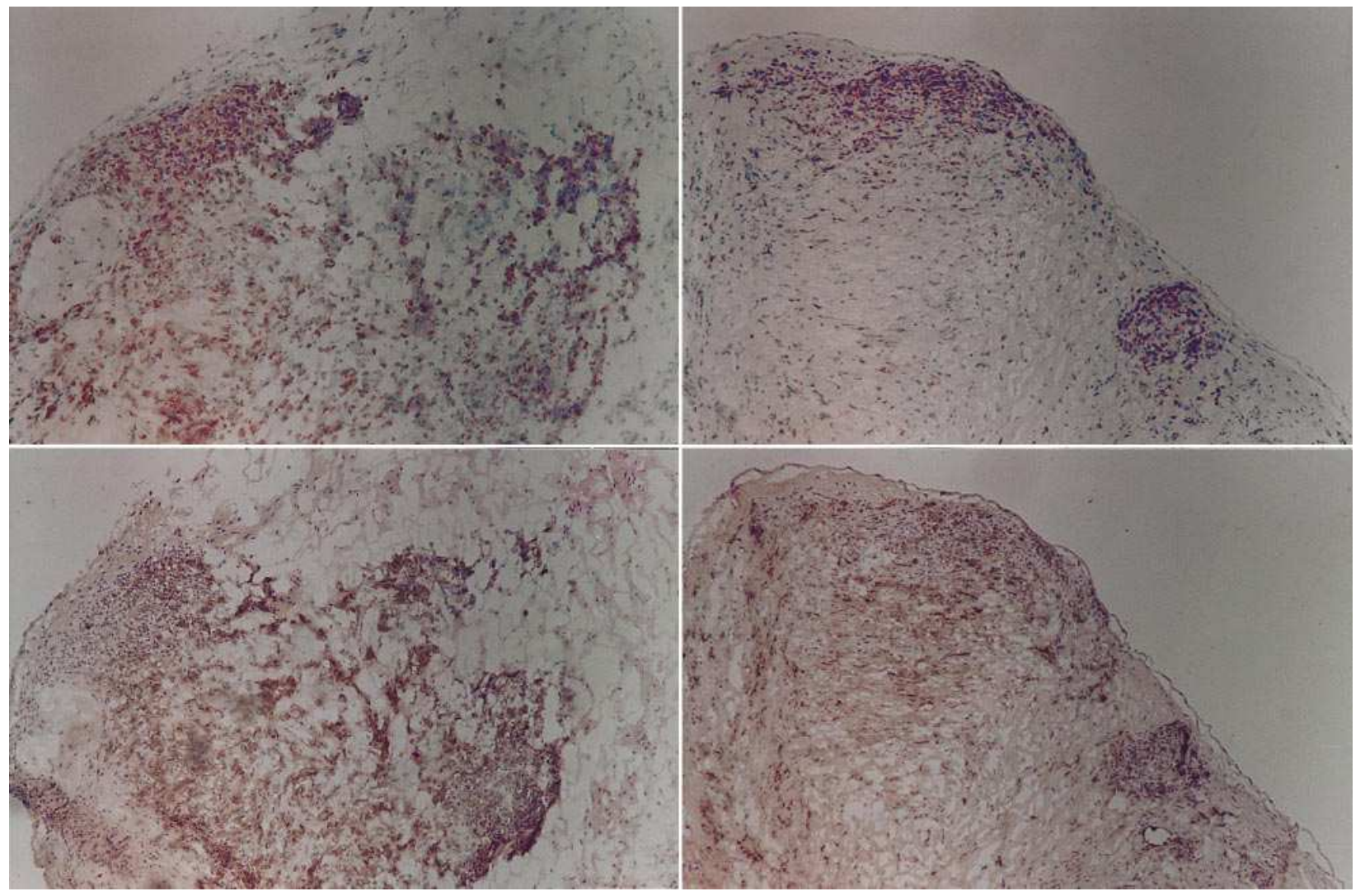

Figure 6. Persistence of the inflammatory infiltrate in chronically treated GCA-mouse chimera. NOD-SCID mice implanted with temporal artery specimens were either sham-treated or treated with dexamethasone, $0.4 \mathrm{mg} / \mathrm{kg}$, for $28 \mathrm{~d}$. Immunohistochemistry with anti-CD3 (top) and antiCD68 antibodies (bottom) in untreated (left) and treated mice (right) are shown. Infiltration with T cells as well as macrophages persisted. $\times 100$. 

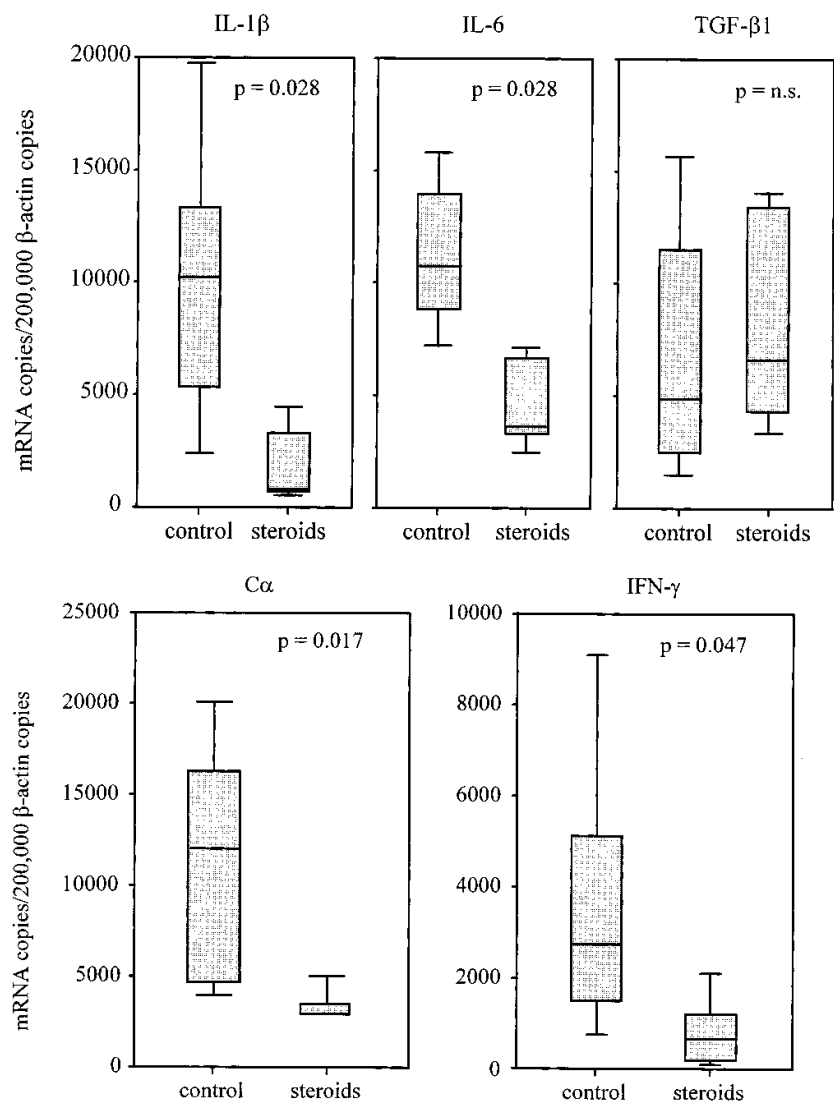

Figure 7. Persistent TGF- $\beta 1$ production in the absence of T cell activation in chronically treated GCA-mouse chimeras. Human tissueSCID mouse chimeras were treated as described in Fig. 6. In situ cytokine transcription in retrieved tissues was determined by semiquantitative PCR. Results from three experiments using five untreated and six treated mice are shown as box graphs displaying medians, 25th and 75th percentiles, and 10th and 90th percentiles, as whiskers.

\section{Discussion}

Glucocorticoid responsiveness is a common denominator of most human autoimmune diseases (15). Therapeutic benefits from steroid therapy have indeed been cited as evidence for the contribution of the immune system to chronic inflammatory diseases, and glucocorticoids are considered quintessential immunosuppressants. Although in vitro molecular studies have provided information on the cellular pathways, very little is known on the action of chronic steroid therapy in vivo in human diseases. Initially, glucocorticoids were shown to suppress the AP-1 (c-jun/c-fos) transcription factor (6-9). More recently, evidence has been provided that glucocorticoids function by blocking the nuclear translocation and DNA binding of $\mathrm{NF} \kappa \mathrm{B}$ through the induction of the IкB $\alpha$ protein and cytoplasmic trapping of $\mathrm{NF \kappa B}(10,11)$. NFKB is involved in the inducible regulation of a large spectrum of genes, several of which play a role in the function of immune cells and encode for inflammatory mediators (16). How transrepression of cytokines changes the interaction of cells accumulated in chronic inflammatory lesions has not been studied. Here we are presenting data on steroid-mediated effects in vivo induced with short- as well as long-term treatment in a human inflammatory disease.
These studies were facilitated by the availability of a human tissue-SCID mouse chimera model in which the inflammation characteristic for patients with GCA was self-sustained and persisted for at least 2 mo (12). The short-term effects of steroid treatment were characterized by a differential modulation of cytokines in the infiltrate which correlated with the induction of IкB $\alpha$ and the reduced availability of free nuclear NFkB. In addition to these pharmacological effects, the long-term treatment allowed conclusions on the biology of the infiltrate under immunosuppression. The continuous immunosuppressant action of NFKB inhibition was sufficient to paralyze the $\mathrm{T}$ cell component of the disease, however, the inflammatory infiltrate of $\mathrm{T}$ cells and macrophages persisted, and macrophages continued to transcribe cytokine mRNA in the absence of $\mathrm{T}$ cell stimulation. A persistent activation of selected inflammatory cells in the lesions would explain the immediate relapse of disease activity after discontinuation of steroid therapy.

GCA is a typical example of a chronic inflammatory disease. Clinical manifestations of the disease are either related to tissue damage resulting from the obstruction of blood supply because of occlusion of inflamed arteries, or from systemic symptoms associated with an acute phase reaction. Previous studies have provided evidence that the constitutional symptoms are linked closely to the presence of elevated levels of circulating IL-6 (17). IL-6 is a potent inducer of acute-phase proteins, and could thus explain the principle laboratory abnormalities in patients diagnosed with GCA (18). IL-6 is produced by circulating monocytes as well as by tissue-infiltrating macrophages (19). GCA tissue-SCID mice chimera have elevated serum concentrations of human IL-6, documenting that even a small fragment of inflamed tissue has systemic effects (Brack, A., unpublished observations). Since the IL-6 gene is regulated by $\mathrm{NF \kappa B}$ and thus should be subject to a rapid immunosuppressive action of glucocorticoids, it can be predicted that steroids induce a prompt improvement. Besides IL-6, several other inflammatory cytokines have been implicated in the disease process. $\mathrm{T}$ cells accumulated in the arterial walls display a stringent pattern of cytokine production in that IL-2 and IFN- $\gamma$ are consistently found in the lesions. TH2 T cell type cytokines such as IL-4 or IL-5 are not detectable. IFN- $\gamma$ appears to play a central role in shaping the disease process. The in situ IFN- $\gamma$ transcription has been related to the development of full-blown vasculitis, as opposed to subclinical vascular inflammation in patients with polymyalgia rheumatica, a forme fruste of GCA (3). Tissue concentrations of IFN- $\gamma$ are predictive of the formation of multinucleated giant cells, a cell population which has been assumed to have a role in the destruction of elastic tissue (20). Patients with high production of IFN- $\gamma$ in the affected arteries are more likely to develop manifestations of cranial arteritis with blindness, jaw claudication, and central nervous system disease. Taken together, IFN- $\gamma$ seems to act as a cardinal amplificator of the disease.

The production of IFN- $\gamma$ was relatively insensitive to the immediate immunosuppressive effects of steroids, possibly due to the lack of an NFKB binding site in the IFN- $\gamma$ gene. With high doses of steroids or prolonged treatment, suppression of IFN- $\gamma$ production was seen, which may reflect an attenuation of the $\mathrm{T}$ cell response in general rather than a direct effect of dexamethasone on IFN- $\gamma$ transcription. Inhibition of IFN- $\gamma$ should remove a central player of the disease, and it would be expected that the suppression of IFN- $\gamma$ is followed by the dis- 
appearance of activated macrophages. This progression was indeed the case for the production of IL-1 $\beta$, however, data presented here document that macrophage activation persists despite almost complete suppression of IFN- $\gamma$. Steroids selectively inhibited IL-1 $\beta$ and IL-6 while leaving TGF- $\beta 1$ transcription unaffected. Previous data have suggested that the effect of steroids on the expression of TGF- $\beta 1$ is not uniform, and that induction as well as suppression of TGF- $\beta$ transcription, can be found dependent of the tissue studied $(21,22)$. The persistence of TGF- $\beta 1$ production in steroid-treated GCA tissue may have more detrimental than beneficial effects. Depending on the microenvironment and the local tissue concentrations, TGF- $\beta$ can be considered as an anti- as well as a proinflammatory cytokine (23-27). TGF- $\beta$ is mainly produced by adventitial macrophages. The close vicinity of TGF- $\beta$ production to the vasa vasorum could provide ideal circumstances to exert chemotactic activity, and to recruit macrophages into the inflammatory process $(28,29)$.

In contrast to adventitial macrophages, intimal macrophages synthesize iNOS, which catalyzes the synthesis of NO. iNOS production in the inflamed arteries is highly sensitive to steroid-mediated repression, again consistent with the expression of an NFKB binding site. The biological consequences of the suppression of NO production are unclear. NO has been proven to have proinflammatory effects in chronic inflammatory diseases, as well as in experimental models of arthritis (30, 31). NO, however, is also involved in inhibiting platelet adhesion and smooth muscle cell proliferation, and facilitates vasodilatation (32). Considering that NO is preferentially produced in the intima, and that many clinical manifestations of the arteritis are related to blood vessel occlusion, iNOS induction could serve as a protective mechanism. The rapid suppression by steroids possibly represents an unwanted effect of the therapeutic intervention.

In summary, several conclusions can be drawn from the analysis of steroid-treated GCA-SCID chimeras. Consistent with the in vitro findings, administration of steroids downregulated nuclear $\mathrm{NF \kappa B}$, and subsequently repressed genes under transcriptional control of NFkB. While the suppression of inflammatory cytokines might have a beneficial outcome, the prompt reduction in iNOS might actually weaken protective mechanisms. More importantly, high doses of glucocorticoids were necessary to accomplish blockade of cytoplasmic NFkB activation by $\mathrm{I}_{\kappa} \mathrm{B} \alpha$ and the subsequent inhibition of cytokine synthesis. These doses were 4-40-fold higher than the doses generally recommended for the treatment of GCA, but are in the range of doses used for in vitro induction of IкB $\alpha$ transcription (10). Although it appears that minor variations in cytokine concentrations already have significant clinical consequences, administration of higher steroid doses in the early treatment of GCA might improve the immunosuppressant effect. Increased efficiency in blocking cytokines in the early stages of the disease may reduce steroid requirements in the long-term management, and thus reduce the high risk for GCA patients to develop steroid-induced side effects. Finally, the resistance of TGF- $\beta 1$ production to steroid treatment suggests that TGF- $\beta 1+$ macrophages appear to function in the absence of $\mathrm{T}$ cell stimulatory signals. It is possible that TGF- $\beta 1$ mRNA is merely an indicator for persistent macrophage activation, and other macrophage-derived products are also produced in the vascular lesions. In that case, suppressing TGF- $\beta 1$ activity ultimately might not be sufficient to induce disease re- mission. Tissue-residing macrophages, however, might provide a suitable target in attempts to complement steroid-mediated immunosuppression.

\section{Acknowledgments}

We thank Toni L. Higgins for outstanding secretarial assistance, Dr. Johannes Björnsson, Department of Pathology, and Dr. Gene Hunder, Division of Rheumatology, for their support, and the patients who donated the tissue to make these studies possible.

A. Brack and H. Rittner were supported by a fellowship from the Deutsche Forschungsgemeinschaft. This work was supported in part by a grant from the Research to Prevent Blindness, Inc., New York, (Research to Prevent Blindness No. 3) and the Mayo Foundation.

\section{References}

1. Huston, K.A., G.G. Hunder, J.T. Lie, R.H. Kennedy, and L.R. Elveback. 1978. Temporal arteritis: a 25-year epidemiologic, clinical, and pathologic study. Ann. Intern. Med. 88:162-167.

2. Weyand, C.M., J. Schönberger, U. Oppitz, N.N.H. Hunder, K.C. Hicok, and J.J. Goronzy. 1994. Distinct vascular lesions in giant cell arteritis share identical T cell clonotypes. J. Exp. Med. 179:951-960.

3. Weyand, C.M., K.C. Hicok, G.G. Hunder, and J.J. Goronzy. 1994. Tissue cytokine patterns in polymyalgia rheumatica and giant cell arteritis. Ann. Intern. Med. 121:484-491.

4. Weyand, C.M., A.D. Wagner, J. Björnsson, and J.J. Goronzy. 1996. Correlation of topographical arrangement and the functional pattern of tissue-infiltrating macrophages in giant cell arteritis. J. Clin. Invest. 98:1642-1649.

5. Wagner, A.D., J. Björnsson, G.B. Bartley, J.J. Goronzy, and C.M. Weyand. 1996. Interferon gamma producing T cells in giant cell vasculitis represent a minority of tissue infiltrating cells and are located distant from the site of pathology. Am. J. Pathol. 148:1925-1933.

6. Yang-Yen, H.F., J.C. Chambard, Y.L. Sun, T. Smeal, T.J. Schmidt, J. Drouin, and M. Karin. 1990. Transcriptional interference between c-Jun and the glucocorticoid receptor: mutual inhibition of DNA binding due to direct protein-protein interaction. Cell. 62:1205-1215.

7. Schule, R., P. Rangarajan, S. Kliewer, L.J. Ransone, J. Bolado, N. Yang, I.M. Verma, and R.M. Evans. 1990. Functional antagonism between oncoprotein c-Jun and the glucocorticoid receptor. Cell. 62:1217-1226.

8. Jonat, C., H.J. Rahmsdorf, K.K. Park, A.C. Cato, S. Gebel, H. Ponta, and P. Herrlich. 1990. Antitumor promotion and antiinflammation: down-modulation of AP-1 (Fos/Jun) activity by glucocorticoid hormone. Cell. 62:1189-1204.

9. Paliogianni, F., A. Raptis, S.S. Ahuja, S.M. Najjar, and D.T. Boumpas. 1993. Negative transcription regulation of the human interleukin-2 gene by glucocorticoids through interference with nuclear factors AP-1 and NF-AT. $J$. Clin. Invest. 91:1481-1489.

10. Scheinman, R.I., P.C. Cogswell, A.K. Lofquist, and A.S. Baldwin. 1995. Role of transcriptional activation of $\mathrm{I} \kappa \mathrm{B} \alpha$ in mediation of immunosuppression of glucocorticoids. Science (Wash. DC). 270:283-286.

11. Auphan, N., J.A. DiDonato, C. Rosette, A. Helmberg, and M. Karin. 1995. Immunosuppression by glucocorticoids: inhibition of NF- $\mathrm{B}$ activity through induction of IкB synthesis. Science (Wash. DC). 270:286-290.

12. Brack, A., V. Martinez-Taboada, J. Björnsson, B.R. Younge, C.M. Weyand, and J.J. Goronzy. 1995. Persistence of giant cell vasculitis in xenotransplants indicates the presence of a disease relevant antigen residing in the arterial wall. Arthritis Rheum. 38:S404(Abstr.).

13. Kaltschmidt, C., B. Kaltschmidt, T. Henkel, H. Stockinger, and P.A. Baeuerle. 1995. Selective recognition of the activated form of transcription factor NF-кB by a monoclonal antibody. Biol. Chem. Hoppe-Seyler. 376:9-16.

14. Schreck, R., B. Meier, D.N. Männel, W. Dröge, and P.A. Baeuerle. 1992. Dithiocarbamates as potent inhibitors of nuclear factor $\kappa B$ activation in intact cells. J. Exp. Med. 175:1181-1194.

15. Boumpas, D., G.P. Chrousos, R.L. Wilder, T.R. Cupps, and J.E. Balow. 1993. Glucocorticoid therapy for immune-mediated diseases: basic and clinical correlates. Ann. Intern. Med. 119:1198-1208.

16. Baldwin, A.S. 1996. The NFкB and IкB proteins-New discoveries and insights. Annu. Rev. Immunol. 14:649-683.

17. Roche, N.E., J.W. Fulbright, A.D. Wagner, G.G. Hunder, J.J. Goronzy, and C.M. Weyand. 1993. Correlation of interleukin-6 production and disease activity in polymyalgia rheumatica and giant cell arteritis. Arthritis Rheum. 36: 1286-1294.

18. Yoshizaki, K., T. Kuritani, and T. Kishimoto. 1992. Interleukin-6 in autoimmune disorders. Semin. Immunol. 4:155-166.

19. Wagner, A.D., J.J. Goronzy, and C.M. Weyand. 1994. Functional profile of tissue infiltrating and circulating $\mathrm{CD}^{+} 8^{+}$cells in giant cell arteritis. Evidence for two components of the disease. J. Clin. Invest. 94:1134-1140. 
20. Weyand, C.M., N. Tetzlaff, J. Björnsson, and J.J. Goronzy. 1997. Disease patterns and tissue cytokine profiles in giant cell arteritis. Arthritis Rheum. 40:19-26.

21. AyanlarBatuman, O., A.P. Ferrero, A. Diaz, and S.A. Jimenez. 1991. Regulation of transforming growth factor-beta 1 gene expression by glucocorticoids in normal human T lymphocytes. J. Clin. Invest. 88:1574-1580.

22. Batuman, O.A., A. Ferrero, C. Cupp, S.A. Jimenez, and K. Khalili. 1995. Differential regulation of transforming growth factor beta-1 gene expression by glucocorticoids in human T and glial cells. J. Immunol. 155:4397-4405.

23. Wahl, S.M. 1994. Transforming growth factor beta: the good, the bad, and the ugly. J. Exp. Med. 180:1587-1590.

24. Lowrance, J.H., F.X. O'Sullivan, T.E. Caver, W. Waegell, and H.D. Gresham. 1994. Spontaneous elaboration of transforming growth factor $\beta$ suppresses host defense against bacterial infection in autoimmune MRL/lpr mice. J. Exp. Med. 180:1693-1703.

25. Barral-Netto, M., A. Barral, C.E. Brownell, Y.A. Skeiky, L.R. Ellingsworth, D.R. Twardzik, and S.G. Reed. 1992. Transforming growth factor- $\beta$ in leishmanial infection: a parasite escape mechanism. Science (Wash. DC). 257: $545-548$.

26. Allen, J.B., C.L. Manthey, A.R. Hand, K. Ohura, L. Ellingsworth, and
S.M. Wahl. 1990. Rapid onset synovial inflammation and hyperplasia induced by transforming growth factor $\beta$. J. Exp. Med. 171:231-247.

27. Wahl, S.M., J.B. Allen, G.L. Costa, H.L. Wong, and J.R. Dasch. 1993. Reversal of acute and chronic synovial inflammation by anti-transforming growth factor $\beta$. J. Exp. Med. 177:225-230.

28. Wahl, S.M., D.A. Hunt, L.M. Wakefield, N. McCartney-Francis, L.M. Wahl, A.B. Roberts, and M.B. Sporn. 1987. Transforming growth factor type beta induces monocyte chemotaxis and growth factor production. Proc. Natl. Acad. Sci. USA. 84:5788-5792.

29. Wahl, S.M., J.B. Allen, B.S. Weeks, H.L. Wong, and P.E. Klotman. 1993. TGF- $\beta$ enhances integrin expression and type IV collagenase secretion in human monocytes. Proc. Natl. Acad. Sci. USA. 90:4577-4581.

30. McCartney-Francis, N., J.B. Allen, D.E. Mizel, J.E. Albina, Q.W. Xie, C.F. Nathan, and S.M. Wahl. 1993. Suppression of arthritis by an inhibitor of nitric oxide synthase. J. Exp. Med. 178:749-754.

31. Clancy, R.M., and S.B. Abramson. 1995. Nitric oxide. A novel mediator of inflammation. Proc. Soc. Exp. Biol. Med. 210:93-101.

32. Luscher, T.F., R.R. Wenzel, and G. Noll. 1995. Local regulation of the coronary circulation in health and disease: role of nitric oxide and endothelin. Eur. Heart. J. 16(Suppl. C):51-58. 